\title{
Hedgehog signaling pathway regulates human pancreatic cancer cell proliferation and metastasis
}

\author{
KUN HAO ${ }^{*}$, XIAO-DONG TIAN ${ }^{*}$, CHANG-FU QIN, XUE-HAI XIE and YIN-MO YANG \\ Department of General Surgery, Peking University First Hospital, Beijing 100034, P.R. China
}

Received October 22, 2012; Accepted November 30, 2012

DOI: $10.3892 /$ or.2012.2210

\begin{abstract}
Pancreatic cancer is one of the most aggressive and devastating malignancies. The Hedgehog $(\mathrm{Hh})$ pathway has been reported to play an important role in pancreatic cancer development and progression. The aim of this study was to examine the activation of the Hh pathway in human pancreatic cancer tissue samples and pancreatic cancer cell lines, and the molecular mechanisms involved in the $\mathrm{Hh}$ pathway mediated effects on pancreatic cancer cell proliferation and invasion. The expression levels of $\mathrm{Hh}$ molecules in human pancreatic cancer tissue samples and pancreatic cancer cell lines were evaluated using RT-PCR. The role of the Hh pathway in cell proliferation and invasion was evaluated using flow cytometry, MTT, colony formation assays and Transwell invasion assays, and the expression of cancer stem cell markers and epithelial-mesenchymal transition (EMT) were evaluated using flow cytometry and RT-PCR. Tumorigenicity assays were used to further investigate the role of the Hh pathway in vivo. Hh molecules were highly expressed in human pancreatic cancer tissue samples and pancreatic cancer cell lines. Inhibition of the Hh pathway notably decreased cell proliferation and induced apoptosis through inhibition of the PI3K/AKT pathway and cancer stem cells. Furthermore, inhibition of the Hh signaling pathway significantly inhibited EMT by suppressing the activation of transcription factors Snail and Slug, which are correlated with significantly reduced pancreatic cancer cell invasion, suggesting that the Hh signaling pathway is involved in early metastasis. These results indicate that activation of the $\mathrm{Hh}$ pathway is a common event. Inhibition of the Hh pathway may be a potential molecular target of new therapeutic strategies for pancreatic cancer.
\end{abstract}

Correspondence to: Professor Yin-Mo Yang, Department of General Surgery, Peking University First Hospital, 8th Xishiku Street, Xicheng, Beijing 100034, P.R. China

E-mail: yangyinmo@263.net

"Contributed equally

Key words: Hedgehog, pancreatic cancer, cancer stem cell, epithelial-mesenchymal transition

\section{Introduction}

Pancreatic cancer is one of the most devastating malignancies worldwide, and the fourth leading cause of cancer-related death in the United States. It was estimated that in 2011, 44,030 new cases would be diagnosed with pancreatic cancer and 37,660 individuals would die from this disease (1). Pancreatic cancer has the worst prognosis of all human tumors. Only approximately $20 \%$ of pancreatic cancer patients are eligible for surgical resection; most pancreatic cancers are not resectable at the time of diagnosis. In addition, there are limited treatment options available. Chemotherapies and radiotherapies are largely ineffective, and metastatic disease frequently recurs even after surgical resection of primary lesions (2-4). Recently, a number of risk factors have been identified, including age, cigarette smoking, high dietary intake of meat and fat, low serum folate levels, obesity, long-standing diabetes mellitus, chronic pancreatitis and family history (5), but exactly how these risk factors contribute to carcinogenesis remains largely unknown. Therefore, novel strategies for the prevention of tumor progression and metastasis are urgently needed.

The cancer stem cell (CSC) hypothesis provides novel molecular targets and strategies for prevention of pancreatic cancer. CSCs may be responsible for tumor onset, maintenance, mutation accumulation and metastasis due to their ability to express anti-apoptotic and multidrug resistanceassociated proteins, thus sustaining tumor growth (6-9). Conventional therapeutic approaches merely kill the majority of differentiated tumor cells, except for CSCs, which have intrinsic detoxifying mechanisms and can easily elude these therapies. Recently, CSCs and epithelial-mesenchymal transition (EMT)-type cells, which share molecular characteristics with CSCs, have been proposed to play critical roles in chemoresistance and metastasis as demonstrated in several malignancies including pancreatic cancer. Thus, it has become increasingly important to increase our understanding, at the molecular level, of the features of CSCs and EMT in pancreatic cancer. Such knowledge is likely to be helpful in the discovery of novel molecular targets for the prevention of this disease.

The Hedgehog (Hh) signaling pathway functions postembryonically in the development and homeostasis of many organs and tissues through its effects on stem or progenitor cells. Aberrant activation of the Hh signaling pathway correlates with a variety of human tumors where the pathway is implicated in tumorigenesis, malignancy, metastasis and 
cancer stem cells (10-13). Our previous study identified that activation of this pathway was a key event in the histogenesis of pancreatic cancer (14). In a transgenic mouse model of pancreatic cancer, inhibition of the Hh signaling pathway was found to reduce tumor-associated stromal tissues and to ameliorate gemcitabine uptake in tumor cells (15). Recent studies found that activation of the Shh signaling pathway was involved in the regulation of CSC self-renewal, differentiation and tumorigenic potential, suggesting that the Shh signaling pathway may be a novel therapeutic approach for the treatment of pancreatic cancer (16-19). In the present study, the expression of $\mathrm{Hh}$ molecules in human pancreatic cancer tissue samples and pancreatic cancer cell lines was detected. In addition, the effects of $\mathrm{Hh}$ signaling pathway on pancreatic cancer cell proliferation and invasion were evaluated. Finally, the molecular mechanisms by which inhibition of the $\mathrm{Hh}$ signaling pathway decreased cell proliferation, invasion and induced apoptosis were assessed.

\section{Materials and methods}

Tissue samples and cell lines. A total of 54 human pancreatic cancer tissue samples were collected from the Peking University First Hospital. Informed consent of the patients was obtained before surgical resection, and this study was approved by the Research Ethics Committee of Peking University First Hospital. Pancreatic cancer cell lines (PANC-1, ASPC-1 and Mia PaCa-2) were cultured in Dulbecco's modified Eagle's medium (DMEM; Gibco, Invitrogen, Carlsbad, CA, USA) supplemented with $10 \%$ fetal bovine serum (FBS; Sigma, St. Louis, MO, USA), penicillin (100 U/ml) and streptomycin (100 $\mu \mathrm{g} / \mathrm{ml})$.

Establishment of pancreatic cancer cell clones expressing SMO RNAi. The RNAi targeting the human SMO gene (GenBank accession no. NM_005631) and the negative control sequence were designed and constructed by GeneChem (Shanghai, China). The sequence of the SMO RNAi was GACTCTGTCCTGCGTCATCAT, and that of the negative control was TTCTCCGAACGTGTCACGT. Briefly, the shRNAs were inserted into pFU-GW-RNAi lentivirus vectors containing the HpaI and XhoI enzyme sites (Fig. 1), and all constructs were confirmed by sequence analysis. PANC-1 cells were transfected with the recombinant lentiviral vectors targeting the SMO gene (PANC-1-si) or the negative control vectors (PANC-1-nc). The constructs were stably transfected into cells to generate knockdown clones. The cells were cultured for $48 \mathrm{~h}$, and the transduction efficiency was assessed using FACS analysis. The transfected cells were harvested and prepared for subsequent studies.

Reverse transcription-polymerase chain reaction (RT-PCR). Total RNA was extracted from pancreatic cancer cells using TRIzol reagent (Invitrogen, Carlsbad, CA, USA). Aliquots $(1 \mu \mathrm{g})$ of RNA were DNase-treated and processed for firststrand cDNA synthesis using the RT-PCR kit (Toyobo, Osaka, Japan). The corresponding cDNA fragments underwent initial denaturation at $94^{\circ} \mathrm{C}$ for $5 \mathrm{~min}$, followed by 35 cycles of denaturation at $94^{\circ} \mathrm{C}$ for $30 \mathrm{sec}$, annealing at $51-57^{\circ} \mathrm{C}$ for $30 \mathrm{sec}$, extension at $72^{\circ} \mathrm{C}$ for $1 \mathrm{~min}$, and a final extension step at $72^{\circ} \mathrm{C}$

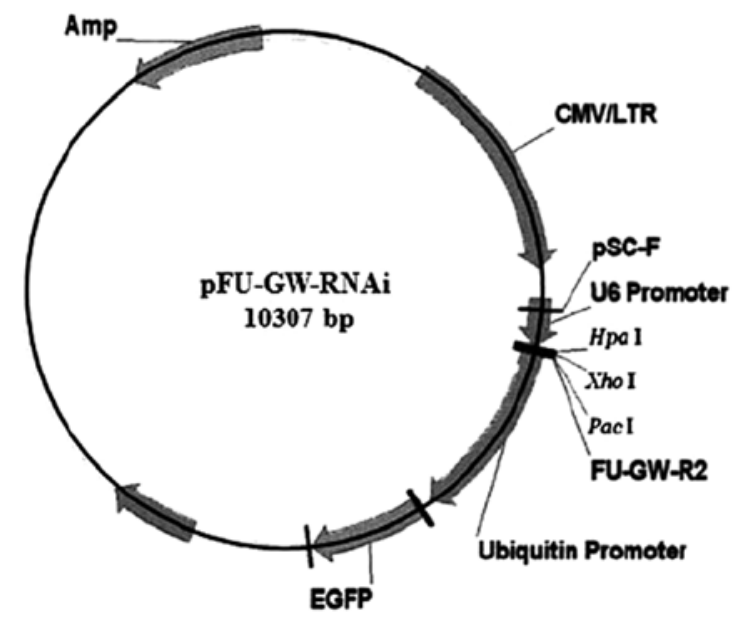

Figure 1. Schematic diagram of the pFU-GW-RNAi vector. The shRNAencoding template was inserted between the $\mathrm{HpaI}$ and $\mathrm{XhoI}$ restriction sites downstream of the U6 promoter.

for $5 \mathrm{~min}$. Amplified products were separated by electrophoresis in a $2 \%$ agarose gel. The primer sequences for RT-PCR are shown in Table I. Three independent experiments were performed.

Real-time reverse transcription-polymerase chain reaction (real-time RT-PCR). Total RNA was extracted from human pancreatic cancer tissue samples using TRIzol reagent (Invitrogen). Aliquots (1 $\mu \mathrm{g})$ of RNA were DNase-treated and processed for first-strand cDNA synthesis using the RT-PCR kit. Real-time RT-PCR was carried out on an Applied Biosystems 7300 Fast Real-time PCR System (Applied Biosystems, Foster City, CA, USA) using real-time PCR Master Mix (Toyobo). Quantification of gene expression was calculated by the $2^{-\Delta \Delta C t}$ method. GAPDH was used as an internal control. The primer sequences for real-time RT-PCR are shown in Table I.

Western blot analysis. Pancreatic cancer cell lines were seeded in $10-\mathrm{cm}$ cell culture plates in complete medium and allowed to reach $80 \%$ confluency. Then, cells were lysed and the proteins were obtained using the Total Protein Extraction kit (KeyGen, Nanjing, China). Total protein (70 $\mu \mathrm{g} / \mathrm{sample})$ was separated by sodium dodecyl sulfate-polyacrylamide gel electrophoresis (SDS-PAGE). After being transferred to nitrocellulose membranes, blots were incubated with the SMO antibody (Chemicon International, Temecula, CA, USA) and $\beta$-actin antibody (Zsbio, Beijing, China), and the washed blots were then incubated with secondary antibodies conjugated with horseradish peroxidase. To detect the activation of the PI3K/AKT pathway, pancreatic cancer cells (PANC-1-si and PANC-1-nc) were treated with Shh $(1 \mu \mathrm{g} / \mathrm{ml}$, Abcam, Cambridge, UK), and then western blot analysis was performed with the phospho-AKT antibody (Cell Signaling Technology, Beverly, MA, USA). Three independent experiments were performed.

MTT assays. Pancreatic cancer cells were propagated in 96-well plates at a density of $5.0 \times 10^{3}$ cells/well for $72 \mathrm{~h}$ prior to the proliferation assays. MTT $(20 \mu \mathrm{l})(5 \mathrm{mg} / \mathrm{ml}$, Sigma) was 
Table I. Primer sequences.

\begin{tabular}{|c|c|c|}
\hline Gene name & & Sequences \\
\hline $\mathrm{SHH}$ & $\begin{array}{l}\text { Sense } \\
\text { Antisense }\end{array}$ & $\begin{array}{l}\text { 5'-CCAATTACAACCCCGACATC-3' } \\
\text { 5'-CAGTTTCACTCCTGGCCACT-3' }\end{array}$ \\
\hline PTCH1 & $\begin{array}{l}\text { Sense } \\
\text { Antisense }\end{array}$ & $\begin{array}{l}\text { 5'-TGGGATTAAAAGCAGCGAAC-3' } \\
\text { 5'-TCTCCAATCTTCTGGCGAGT-3' }\end{array}$ \\
\hline SMO & $\begin{array}{l}\text { Sense } \\
\text { Antisense }\end{array}$ & $\begin{array}{l}\text { 5'-TGCTCATCGTGGGAGGCTACTT-3' } \\
\text { 5'-ATCTTGCTGGCAGCCTTCTCAC-3' }\end{array}$ \\
\hline GLI1 & $\begin{array}{l}\text { Sense } \\
\text { Antisense }\end{array}$ & $\begin{array}{l}\text { 5'-TATGGACCTGGCTTTGGA-3' } \\
\text { 5'-CCTTGTAGACCCAGAAAC-3' }\end{array}$ \\
\hline E-cadherin & $\begin{array}{l}\text { Sense } \\
\text { Antisense }\end{array}$ & $\begin{array}{l}\text { 5'-GCCTCCTGAAAAGAGAGTGGAAG-3' } \\
\text { 5'-TGGCAGTGTCTCTCCAAATCCG-3' }\end{array}$ \\
\hline N-cadherin & $\begin{array}{l}\text { Sense } \\
\text { Antisense }\end{array}$ & $\begin{array}{l}\text { 5'-TCGCTCTCGAGCTCTCCGCCTCCATGTGCCGG-3' } \\
\text { 5'-AAGGGTCACCTGAAGTTCAGTCATCAC-3' }\end{array}$ \\
\hline Vimentin & $\begin{array}{l}\text { Sense } \\
\text { Antisense }\end{array}$ & $\begin{array}{l}\text { 5'-AGGCAAAGCAGGAGTCCACTGA-3' } \\
\text { 5'-ATCTGGCGTTCCAGGGACTCAT-3' }\end{array}$ \\
\hline Fibronectin & $\begin{array}{l}\text { Sense } \\
\text { Antisense }\end{array}$ & $\begin{array}{l}\text { 5'-ACAACACCGAGGTGACTGAGAC-3' } \\
\text { 5'-GGACACAACGATGCTTCCTGAG-3' }\end{array}$ \\
\hline Snail & $\begin{array}{l}\text { Sense } \\
\text { Antisense }\end{array}$ & $\begin{array}{l}\text { 5'-TGCCCTCAAGATGCACATCCGA-3' } \\
\text { 5'-GGGACAGGAGAAGGGCTTCTC-3' }\end{array}$ \\
\hline Slug & $\begin{array}{l}\text { Sense } \\
\text { Antisense }\end{array}$ & $\begin{array}{l}\text { 5'-ATCTGCGGCAAGGCGTTTTCCA-3' } \\
\text { 5'-GAGCCCTCAGATTTGACCTGTC-3' }\end{array}$ \\
\hline GAPDH & $\begin{array}{l}\text { Sense } \\
\text { Antisense }\end{array}$ & $\begin{array}{l}\text { 5'-ACGGATTTGGTCGTATTGGG-3' } \\
\text { 5'-TGATTTTGGAGGGATCTCGC-3' }\end{array}$ \\
\hline
\end{tabular}

added to each well and incubated for $4 \mathrm{~h}$ at $37^{\circ} \mathrm{C}$. Then culture medium was removed, $200 \mu$ l dimethyl sulfoxide (DMSO) was added and thoroughly mixed for $15 \mathrm{~min}$ to resolve the cellular formazan. Optical density was measured at $570 \mathrm{~nm}\left(\mathrm{OD}_{570}\right)$ with an ELISA plate reader (Bio-Rad Laboratories, Hercules, CA, USA). The cell growth inhibition rate (GIR) was calculated as follows: GIR $=\left(1-\mathrm{OD}_{570}\right.$ of treated cells $/ \mathrm{OD}_{570}$ of untreated cells) x $100 \%$. Three independent experiments were performed.

Colony formation assays. Cells $\left(3.0 \times 10^{3}\right.$ cells/plate) were seeded into 60-mm culture dishes and allowed to grow for 14 days. Colonies were fixed in methanol and visible colonies containing $\sim 50$ or more cells were counted. Three independent experiments were performed.

Flow cytometric analysis. An Annexin V-PE Apoptosis Detection kit (BD Biosciences, Franklin Lakes, NJ, USA) was used to measure the apoptosis of pancreatic cancer cells (wild-type, PANC-1-si and PANC-1-nc). The cells were seeded in 6-well plates and incubated until $70 \%$ confluency. The cells were then harvested, washed twice with cold phosphatebuffered saline (PBS), and resuspended in $1 \mathrm{X}$ binding buffer at a concentration of $1.0 \times 10^{6}$ cells $/ \mathrm{ml}$. Solution $(100 \mu \mathrm{l})$ $\left(1.0 \times 10^{5}\right.$ cells) was transferred to a $5-\mathrm{ml}$ culture tube. A total of $5 \mu \mathrm{l}$ of Annexin V-PE and $5 \mu \mathrm{l}$ of 7-AAD were added, and the mixture was incubated for $15 \mathrm{~min}$ at room temperature in the dark. The labeled cells $\left(1.0 \times 10^{4}\right.$ cells/sample $)$ were analyzed using FACScan flow cytometer (BD Biosciences) in conjunction with CellQuest software. To detect the expression of cancer stem cell marker CD133, pancreatic cancer cells (PANC-1-si and PANC-1-nc) were collected, washed with PBS and suspended in PBS at a concentration of $1.0 \times 10^{6}$ cells $/ \mathrm{ml}$, then labeled with CD133-PE (Miltenyi Biotec, Germany) and analyzed using FACScan flow cytometer. Three independent experiments were performed.

Transwell invasion assays. Cells $\left(1.0 \times 10^{5}\right.$ cells/well) were seeded into the upper chamber of a Transwell insert (Costar, Cambridge, MA, USA), which was precoated with the extracellular matrix (ECM) substitute Matrigel (BD Biosciences) in phenol red-free medium. In the lower chamber, phenol red-free DMEM supplemented with $5 \%$ of steroid-depleted fetal bovine serum (Biochrom, Berlin, Germany) acted as the chemoattractant. The cells were then cultured for an additional $48 \mathrm{~h}$. Non-migrating cells were removed from the upper chamber by scraping, and cells remaining on the lower surface of the insert were stained using $0.1 \%$ crystal violet, and the cell number was counted under a microscope. Three independent experiments were performed.

Nude mouse xenograft model. Six-week-old nude mice (BALB/c AnN Crl-nu BR) were maintained in a barrier facility on high efficiency particulate air-filtered racks and fed by 


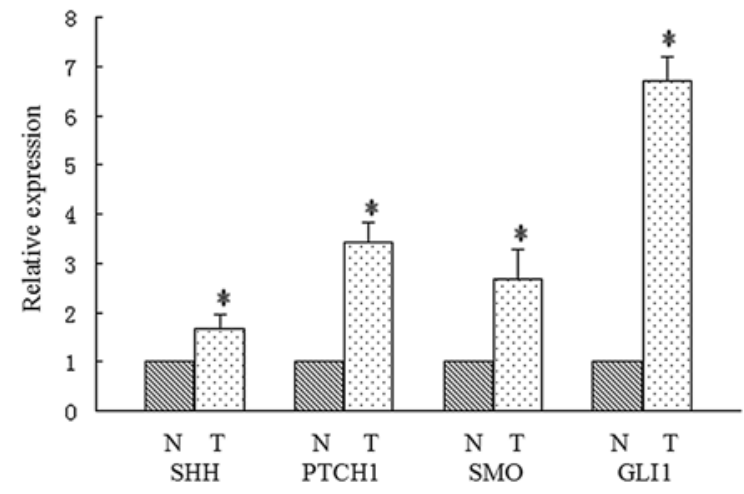

Figure 2. Expression of SHH, PTCH1, SMO and GLI1 in pancreatic cancer tissues and matched adjacent non-tumor tissues. The expression of $\mathrm{Hh}$ molecules in pancreatic cancer tissues (T) and matched adjacent non-tumor tissues (N) was detected by real-time RT-PCR. Quantification of gene expression was calculated by the $2^{-\Delta \Delta_{\mathrm{Ct}}}$ method. GAPDH was used as an internal control. The histogram shows an increase in expression of SHH, PTCH1, SMO and GLI1 in pancreatic cancer tissues when compared with matched adjacent non-tumor tissues. ${ }^{*} \mathrm{P}<0.05$.

breeders from the Department of Laboratory Animal Science, Peking University Health Science Center. Pancreatic cancer cells (wild-type, PANC-1-si and PANC-1-nc) were subcutaneously injected into the right axilla of nude mice. Mice were monitored for tumor formation every 3 days. Tumor size was measured in two dimensions, and the volume was determined by the equation $\mathrm{V}=1 \mathrm{x} \mathrm{w}^{2} \times 0.5$ (where $\mathrm{V}$ is the volume; 1 , length; w, width). Four weeks later, all mice were sacrificed, and tumors were excised. All animal studies were reviewed and approved by the Ethics Committee for Animal Studies at the Peking University, China.

Statistical analysis. Results are presented as the means \pm SD. Statistical analyses were undertaken using SPSS version 13.0. Student's t-test (for two groups) and one-way analysis of variance (ANOVA) test (for multiple groups) followed by the Student-Newman-Keuls (SNK) test were used to assess the differences. $\mathrm{P}<0.05$ was considered to indicate a statistically significant result.

\section{Results}

Activation of the Hh signaling pathway in pancreatic cancer tissue samples and cell lines. We detected SHH, PTCH1, SMO and GLI1 expression in 54 human pancreatic cancer tissue samples for the purpose of evaluating the activation of the Hh signaling pathway. Expression levels of Hh molecules in cancer tissues and matched adjacent non-tumor tissues were determined by real-time RT-PCR. As shown in Fig. 2, a significant difference in expression of $\mathrm{Hh}$ molecules was noted between cancer tissues and matched adjacent non-tumor tissues $(\mathrm{P}<0.05$, respectively). In addition, to confirm the activation of the Hh signaling pathway in pancreatic cancer, we used RT-PCR to detect the expression of SHH, PTCH1, SMO and GLI1 in three pancreatic cancer cell lines (PANC-1, ASPC-1 and Mia PaCa-2). As shown in Fig. 3, varied expression of $\mathrm{Hh}$ molecules confirmed the general presence of an active $\mathrm{Hh}$ signaling pathway. High GLI1 expression was observed in the PANC-1 cell line, which is characterized by poor differen-

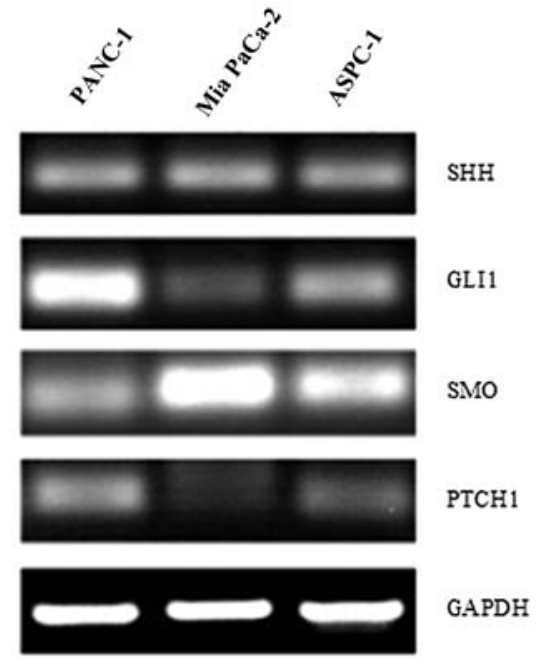

Figure 3. Expression of $\mathrm{Hh}$ molecules in pancreatic cancer cell lines. mRNA expression was detected by RT-PCR in PANC-1, Mia PaCa-2 and ASPC-1 cell lines. GAPDH served as a loading control. All three pancreatic cancer cell lines expressed mRNAs of these molecules.
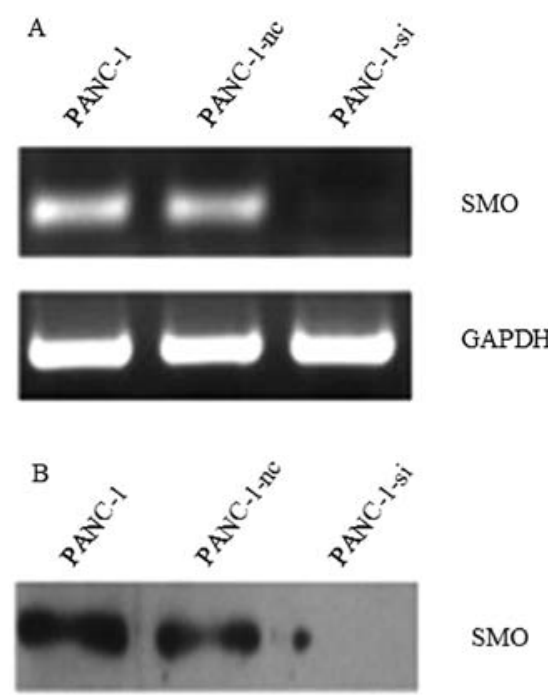

SMO

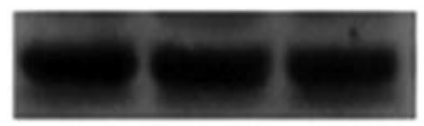

$\beta$-actin

Figure 4. Inhibition of SMO expression in pancreatic cancer cells by lentivirus-mediated shRNA. The mRNA and protein expression of SMO was significantly downregulated in PANC-1-si cells. (A) mRNA expression of SMO was detected by RT-PCR. GAPDH served as a loading control. (B) Protein expression of SMO in pancreatic cancer cells was detected by western blot analysis. $\beta$-actin served as a loading control.

tiation and better invasiveness. In addition, GLI1 is the only reliable marker of Hh signaling pathway activation. Therefore, the PANC-1 cell line was selected for subsequent experiments.

Lentivirus-mediated shRNA targeting SMO decreases cell proliferation and enhances cell apoptosis. PANC-1 cells were transfected with recombinant lentiviral vectors targeting the SMO gene (PANC-1-si) or negative control vectors (PANC-1-nc). The effects of the lentivirus-mediated shRNA on mRNA and protein expression of SMO were examined 


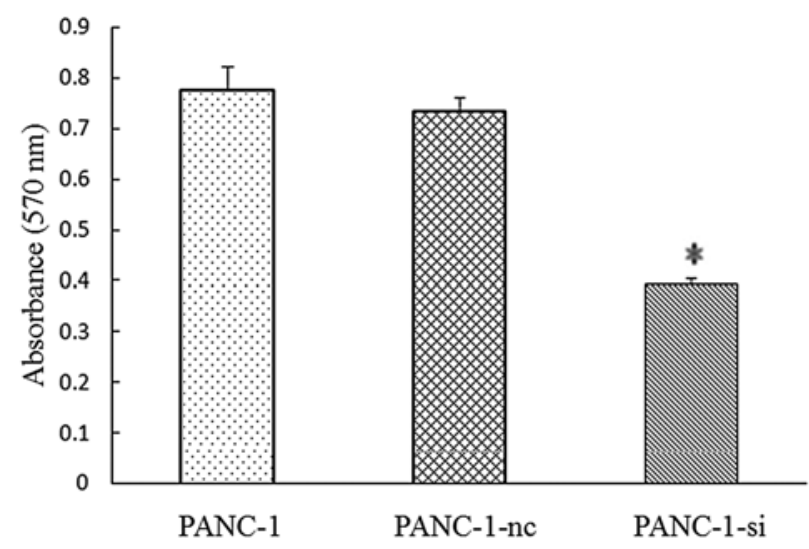

Figure 5. Basal cell proliferation as detected by MTT assay. Cell proliferation was significantly inhibited by knockdown of SMO. Cells were propagated in 96-well plates for $72 \mathrm{~h}$ prior to the proliferation assays. The histogram shows the relative inhibitory ratio compared to the untreated cells. Experiments were performed three times. ${ }^{*} \mathrm{P}<0.05$.

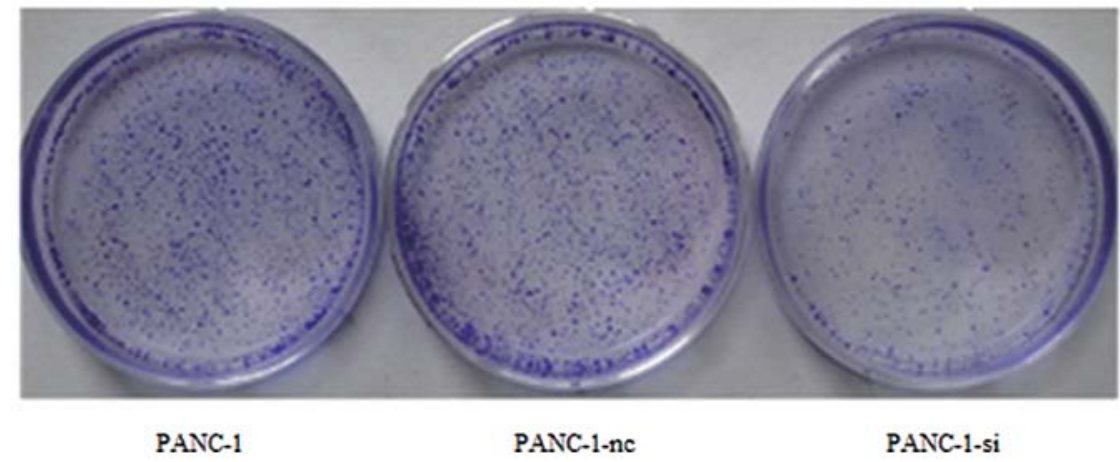

Figure 6. Results of the colony formation assays. Cells were seeded and allowed to grow for 14 days. The PANC-1-si cells grew markedly less colonies than the PANC-1-nc and wild-type cells. Experiments were performed three times.
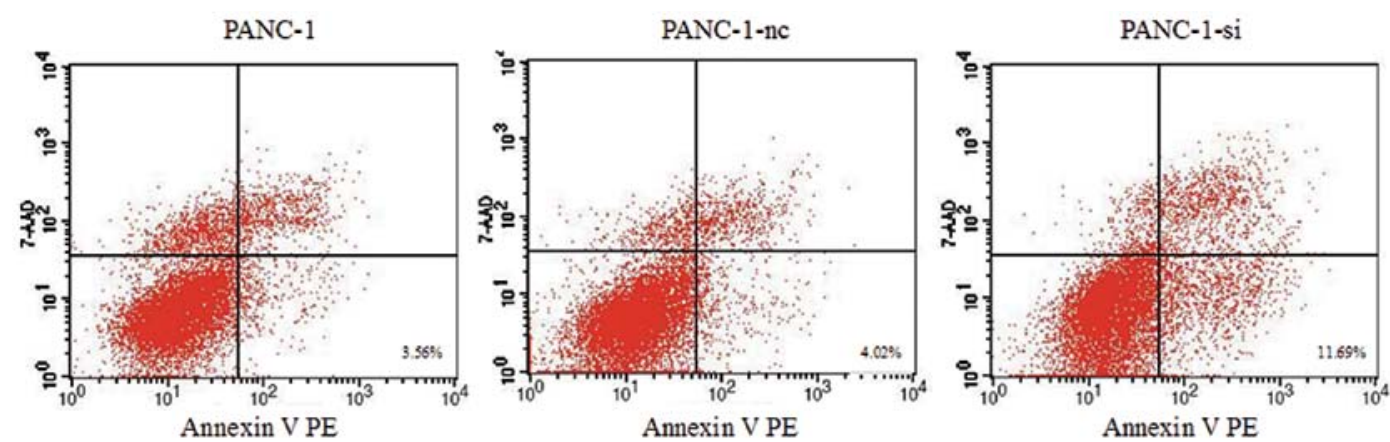

Figure 7. Apoptosis in pancreatic cancer cells detected by FACS analysis. The lower right quadrants represent apoptotic cells, which are Annexin V-PEpositive and 7-AAD-negative, with cytoplasmic membrane integrity. The average apoptotic rates of PANC-1, PANC-1-nc and PANC-1-si cells were 3.56 \pm 0.40 , $4.02 \pm 1.31$ and $11.69 \pm 2.32 \%$, respectively.

by RT-PCR and western blot analysis, and the result revealed that SMO expression was significantly downregulated in PANC-1-si cells (Fig. 4). The effect of lentivirus-mediated shRNA targeting SMO on cell proliferation was measured by MTT and colony formation assays. Pancreatic cancer cells were propagated in 96-well plates for $72 \mathrm{~h}$ prior to the proliferation assays. Inhibition of the Hh signaling pathway significantly decreased the cell proliferation. The average inhibitory rate was $35.7 \pm 1.34 \%$ for PANC-1-si compared with the negative control $(\mathrm{P}<0.05)$ (Fig. 5). In addition, cells were seeded and allowed to grow for 14 days. Visible colonies containing $\sim 50$ or more cells were counted. The results indicated that the number of PANC-1-si colonies was much lower than that of wild-type or negative control cells (Fig. 6). Moreover, SMO suppression caused a moderate increase in the apoptotic rate. As shown in Fig. 7, apoptosis of PANC-1-si cells was markedly increased to $11.69 \pm 1.372 \%$, significantly higher than that of wild-type or negative control cells $(\mathrm{P}<0.05)$. These findings imply that inhibition of the Hh signaling pathway significantly decreases proliferation of PANC-1 cells. To investigate the possible 


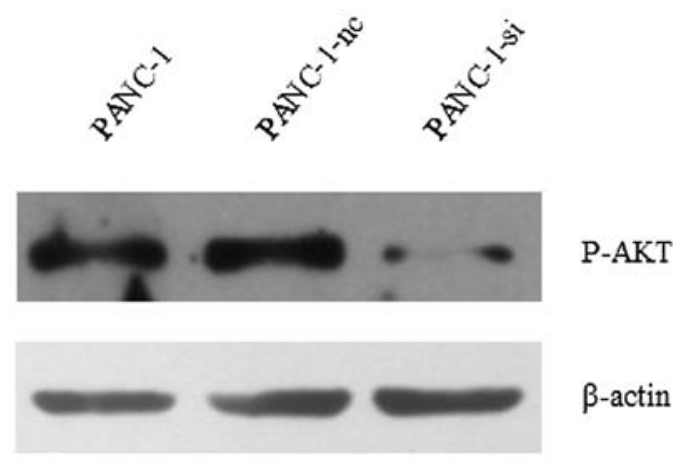

Figure 8. Effect of SMO suppression on the activation of the PI3K/AKT pathway. Cells were treated with Shh prior to assays. Total cellular proteins were subjected to western blot analysis with antibodies directed against phosphorylated AKT. Inhibition of SMO caused a notable decrease in phosphorylated AKT. $\beta$-actin was applied as a control for equal loading.

PANC-1

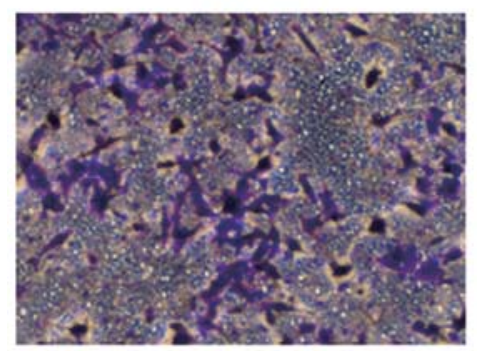

PANC-1-ne

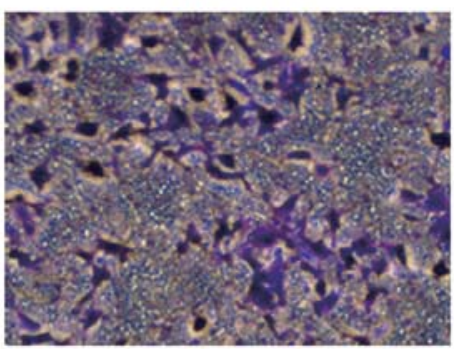

PANC-1-si

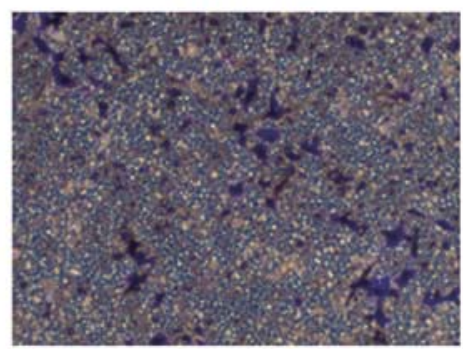

Figure 9. Effect of SMO suppression on cell invasion through filters coated with Matrigel. Invasion through extracellular matrix (ECM) substitute Matrigel was evaluated after $48 \mathrm{~h}$. The number of migrating PANC-1-si cells was significantly lower than that of migrating PANC-1 and PANC-1-nc cells.

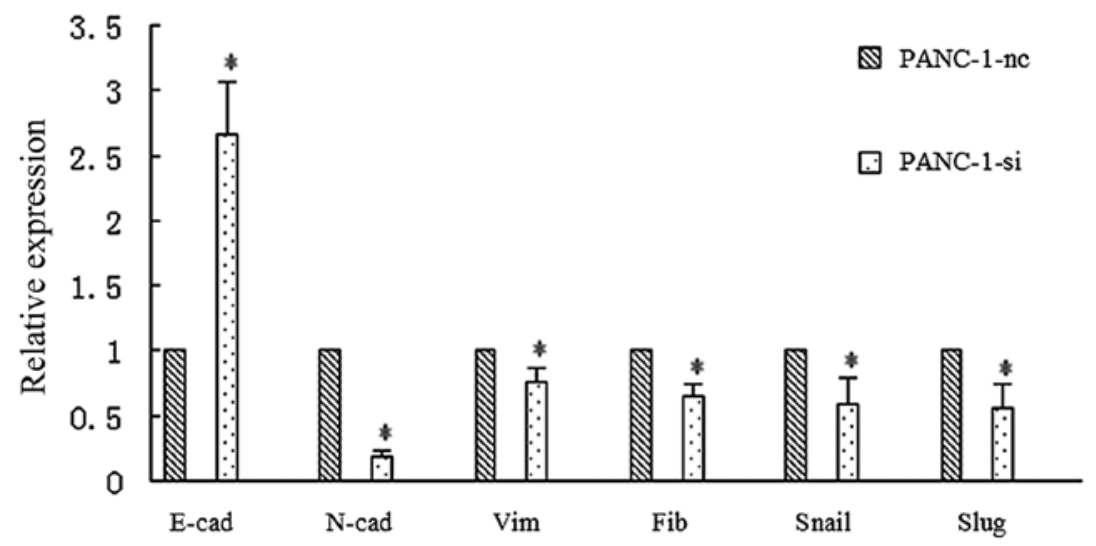

Figure 10. Effect of SMO suppression on EMT. The expression of the epithelial cell surface marker E-cadherin was increased in PANC-1-si, cells whereas the expression levels of the mesenchymal markers N-cadherin, vimentin, fibronectin and transcription factors Snail and Slug were decreased in PANC-1-si. cells ${ }^{*} \mathrm{P}<0.05$. These experiments were performed three times.

mechanisms, we analyzed activation of the PI3K/AKT pathway in pancreatic cancer cells. Pancreatic cancer cells (PANC-1-si and PANC-1-nc) were treated with Shh prior to western blot assays. As shown in Fig. 8, downregulation of SMO caused a notable decrease in phosphorylated AKT.

Lentivirus-mediated shRNA targeting SMO inhibits cell invasion. To further study the potential influence of the $\mathrm{Hh}$ signaling pathway on cancer cell invasion, we performed Transwell invasion assays. As shown in Fig. 9, the number of PANC-1-si cells that migrated through the upper chamber of the Costar wells was less than that of wild-type or negative control cells. Moreover, to test the possibility that the Hh signaling pathway directly drives EMT and metastatic behavior in human pancreatic cancer cells, we analyzed the EMT-related genes by real-time RT-PCR. As shown in Fig. 10, downregulation of SMO caused a notable increase in E-cadherin and a notable decrease in N-cadherin, vimentin and fibronectin. The expression of the transcription factors Snail and Slug also displayed a reduction. Collectively, these 



Figure 11. The CD133+ subfraction in pancreatic cancer cells detected by FACS analysis. The lower right quadrants represent the CD133 ${ }^{+}$subfractions. The percentage of the $\mathrm{CD} 133^{+}$subfractions of PANC-1-nc and PANC-1-si cells were $1.68 \pm 0.121$ and $0.81 \pm 0.178 \%$.

PANC-1

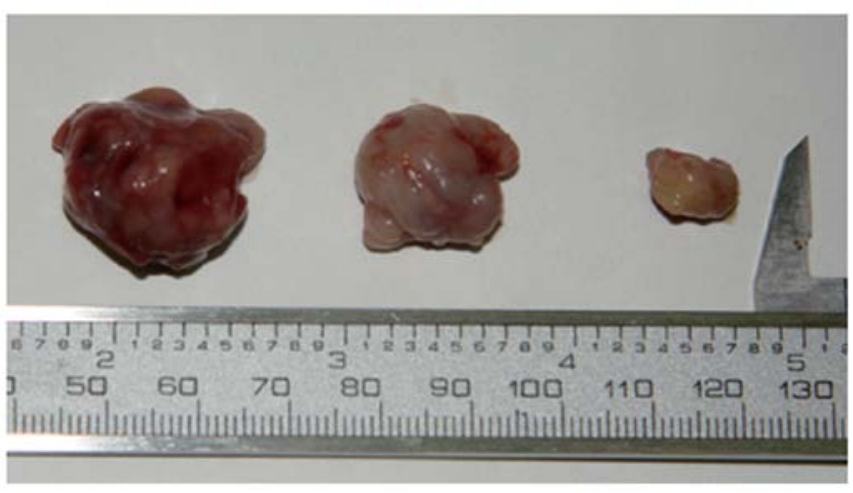

Figure 12. Effect of SMO suppression on the growth of xenograft tumors Pancreatic cancer cells (PANC-1, PANC-1-nc or PANC-1-si) were subcutaneously injected into the right axilla of nude mice. The average tumor volume of PANC-1-si was notably smaller than that of the control groups.

studies demonstrate that the Hh signaling pathway could play a role in the invasion of pancreatic cancer.

Lentivirus-mediated shRNA targeting SMO decreases the expression of a cancer stem cell marker. The involvement of the Hh signaling pathway in proliferation and invasion suggests a possible role in the behavior of pancreatic cancer stem cells. To test cancer stem cell behavior in vitro, we detected the expression levels of cancer stem cell marker CD133 in pancreatic cancer cells. As shown in Fig. 11, our data showed that SMO suppression resulted in downregulation of the CD133 subfraction in PANC-1-si.

Lentivirus-mediated shRNA targeting SMO decreases xenograft tumor growth. To investigate the antitumor effect in vivo, we established xenograft models with PANC-1, PANC-1-nc or PANC-1-si cells. Four weeks later, all mice were sacrificed, and tumors were excised. As shown in Fig. 12, the growth of PANC-1-si xenograft tumors was significantly inhibited when compared with the control groups.

\section{Discussion}

The Hedgehog (Hh) signaling pathway was originally identified through the genetic analysis of segmentation in Drosophila and is highly conserved from insects to vertebrates $(20,21)$. In mammals, there are three Hh ligand proteins: Sonic hedgehog (SHH), Indian hedgehog (IHH) and Desert hedgehog (DHH). They exert their molecular and cellular effects through two transmembrane protein receptors: Patched $(\mathrm{PTCH})$ and Smoothened (SMO), two key regulators of the Hh signaling pathway. PTCH is a 12-transmembrane protein that acts as a negative regulator of SMO, which is a 7-transmembrane protein. When this pathway is activated, Hh ligand proteins activate SMO, complex with coactivator or corepressor proteins, and bind to transcriptional factor GLI in the regulatory regions of target genes to regulate the transcription of GLI-responsive genes $(22,23)$.

Aberrant activation of the Hh signaling pathway has been demonstrated during the progression of human pancreatic cancer. Berman et al (24) analyzed the expression of PTCH mRNA in freshly resected pancreatic tumors by quantitative RT-PCR, and found that PTCH mRNA levels were 69-5,044 times higher in pancreatic tumors (mean, 448; $n=15)$ than in adjacent normal tissue. Kayed et al (25) examined the expression of Hh molecules (IHH, PTCH and SMO) in pancreatic cancer tissues by quantitative RT-PCR, revealing that $\mathrm{IHH}$, PTCH and SMO mRNA levels were increased 35-, 1.2- and 1.6-fold, respectively, compared to normal pancreatic tissues.

In the present study, we evaluated the expression levels of Hh molecules in human pancreatic cancer tissue samples and pancreatic cancer cell lines. Consistent with recent published data (25-28), our results revealed that expression of Hh signaling pathway-related molecules were at a higher level in the cancer tissues than in the matched adjacent non-tumor tissues and existed in all pancreatic cancer cell lines. Although pancreatic cancer tissue samples and cell lines expressed detectable levels of the mRNA of the molecules, the expression levels varied. Little is understood about the exact mechanism of Hh molecules in pancreatic cancer cell proliferation and invasion. Further analysis showed that the therapeutic effects of SMO suppression were correlated with the induction of apoptosis in pancreatic cancer cells. The mechanism of this effect has not yet been fully elucidated. Our results showed that the phosphorylation levels of AKT were markedly reduced in PANC-1-si cells after Shh stimulation compared to control groups (Fig. 8). The results suggests that the suppression of PI3K/AKT activity might be responsible for the apoptosisinducing effect of SMO suppression. As reported by several authors, the PI3K/AKT pathway has also been reported to play 
important roles in the Hh signaling pathway-mediated metastasis and chemoresistance (29-31).

CSCs have been identified in many different types of solid tumors (32-37). Recent evidence indicates that the $\mathrm{Hh}$ signaling pathway is recruited to stimulate CSC growth. It is one of the key pathways that regulates stem cells in the adult body $(38,39)$. Several studies have also shown that the Hh signaling pathway plays an important role in maintaining the biological characteristics of pancreatic cancer stem cells. Hermann and colleagues (40) successfully isolated a different highly tumorigenic subpopulation of pancreatic cancer cells. They found that cells expressing CD133 have the characteristics that defined CSCs, and compared to CD133- pancreatic cancer cells, $\mathrm{CD} 133^{+}$cells showed significantly enhanced resistance to gemcitabine. Dembinski and Krauss (41) found that compared with pancreatic cancer cells, SHH was increased nearly 4-fold in BxPC-3 CSCs and 2-fold in Panc03.27 CSCs, and the zinc finger transcription factor GLI1 was upregulated 2.5-fold in BxPC-3 and 1.5-fold in the Panc03.27 CSC populations. Furthermore, Feldmann et al (42) inhibited the Hh signaling pathway by means of a small-molecule SMO inhibitor, cyclopamine, and found that the treatment preferentially reduced aldehyde dehydrogenase (ALDH)-expressing populations in pancreatic cancer cells; ALDH overexpression is characteristic for stem cells.

In the present study, we found that the Hh signaling pathway may play a role in the regulation of self-renewal in pancreatic cancer stem cells. CD133 expression was analyzed using FACScan flow cytometer in pancreatic cancer cells, which is reported to be a putative marker of CSCs in pancreatic cancer. We demonstrated that the percentage of $\mathrm{CD}_{133}{ }^{+}$cells significantly differed between PANC-1-si and PANC-1-nc cells. The results revealed that inhibition of the Hh signaling pathway by knockdown of SMO affects the pancreatic CSC populative.

Moreover, recent evidence indicates that the $\mathrm{Hh}$ signaling pathway is recruited to orchestrate the reprogramming of cancer cells via EMT in various types of cancer (42-44). EMT is an embryonic program in which epithelial cells lose their characteristics and gain mesenchymal features. Accumulating evidence suggests that EMT plays an important role during malignant tumor progression. Transformed epithelial cells can activate embryonic programs of epithelial plasticity and switch from a sessile, epithelial phenotype to a motile, mesenchymal phenotype. Induction of EMT can, therefore, lead to invasion of surrounding stroma, intravasation, dissemination and colonization of distant sites. It is believed that sustained metastatic growth requires the dissemination of CSCs from the primary tumor followed by its reestablishment in a secondary site. Thus, EMT can confer metastatic ability on carcinomas $(45,46)$. Here, we discovered that inhibition of the Hh signaling pathway can reverse EMT in pancreatic cancer cells. After knockdown of SMO expressions the epithelial cell surface marker E-cadherin increased, the expression of mesenchymal markers $\mathrm{N}$-cadherin, vimentin, fibronectin and transcription factors Snail and Slug decreased and the invasion of PANC-1 cells was inhibited. These characteristics are consistent with the morphological changes, molecular events and functions of mesenchymal-epithelial transition, which is the opposite of EMT.
In conclusion, our data demonstrated that the Hh signaling pathway is frequently activated in human pancreatic cancer tissue samples and pancreatic cancer cells, and plays a pivotal role in maintaining pancreatic cancer cell proliferation and invasion. Inhibition of the $\mathrm{Hh}$ signaling pathway by SMO suppression represents an effective method to decrease cell proliferation and induce apoptosis through inhibition of PI3K/AKT pathways and CSCs. Further studies found that inhibition of the Hh signaling pathway significantly inhibited EMT, suggesting blockade of signaling involved in early metastasis. These data suggest that targeted therapy against the Hh signaling pathway may be beneficial in the treatment of pancreatic cancer.

\section{Acknowledgements}

This research was supported by grants from the National Natural Science Foundation of China (no. 30972897 and 81172184 to Y.M. Yang), and the Overseas Study Program of the China Scholarship Council, Beijing, China. We thank Professor Ze-Bin Mao of the Department of Biochemistry and Molecular Biology in the Peking University Health Science Center for his assistance and technical support.

\section{References}

1. Siegel R, Ward E, Brawley O and Jemal A: Cancer statistics, 2011: the impact of eliminating socioeconomic and racial disparities on premature cancer deaths. CA Cancer J Clin 61: 212-236, 2011.

2. Magee CJ, Ghaneh P and Neoptolemos JP: Surgical and medical therapy for pancreatic carcinoma. Best Pract Res Clin Gastroenterol 16: 435-455, 2002.

3. Yeo TP, Hruban RH, Leach SD, et al: Pancreatic cancer. Curr Probl Cancer 26: 176-275, 2002.

4. Warshaw AL and Fernández-del Castillo C: Pancreatic carcinoma. N Engl J Med 326: 455-465, 1992.

5. Koorstra JB, Hustinx SR, Offerhaus GJ and Maitra A: Pancreatic carcinogenesis. Pancreatology 8: 110-125, 2008.

6. Mueller MT, Hermann PC, Witthauer J, Rubio-Viqueira B, Leicht SF and Huber S: Combined targeted treatment to eliminate tumorigenic cancer stem cells in human pancreatic cancer. Gastroenterology 137: 1102-1113, 2009.

7. Tanaka H, Nakamura M, Kameda C, Kubo M, Sato N and Kuroki S: The Hedgehog signaling pathway plays an essential role in maintaining the $\mathrm{CD} 44^{+} \mathrm{CD} 24^{-} /$low subpopulation and the side population of breast cancer cells. Anticancer Res 29: 2147-2157, 2009.

8. Shankar S, Nall D, Tang SN, Meeker D, Passarini J, Sharma J and Srivastava RK: Resveratrol inhibits pancreatic cancer stem cell characteristics in human and KrasG12D transgenic mice by inhibiting pluripotency maintaining factors and epithelialmesenchymal transition. PLoS One 6: e16530, 2011.

9. Srivastava RK, Tang SN, Zhu W, Meeker D and Shankar S: Sulforaphane synergizes with quercetin to inhibit self-renewal capacity of pancreatic cancer stem cells. Front Biosci 3: 515-528, 2011.

10. Beachy PA, Karhadkar SS and Berman DM: Tissue repair and stem cell renewal in carcinogenesis. Nature 432: 324-331, 2004.

11. Ruiz i Altaba A, Mas C and Stecca B: The Gli code: an information nexus regulating cell fate, stemness and cancer. Trends Cell Biol 17: 438-447, 2007.

12. Ruiz i Altaba A: Therapeutic inhibition of Hedgehog-GLI signaling in cancer: epithelial, stromal, or stem cell targets? Cancer Cell 14: 281-283, 2008.

13. Bailey JM, Singh PK and Hollingsworth MA: Cancer metastasis facilitated by developmental pathways: Sonic hedgehog, Notch, and bone morphogenic proteins. J Cell Biochem 102: 829-839, 2007.

14. Yang $Y$, Tian $X$, Xie $X$, Zhuang $Y, W u ~ W$ and Wang W: Expression and regulation of hedgehog signaling pathway in pancreatic cancer. Langenbecks Arch Surg 395: 515-525, 2010. 
15. Olive KP, Jacobetz MA, Davidson CJ, et al: Inhibition of Hedgehog signaling enhances delivery of chemotherapy in a mouse model of pancreatic cancer. Science 324: 1457-1461, 2009.

16. Lee CJ, Dosch J and Simeone DM: Pancreatic cancer stem cells. J Clin Oncol 26: 2806-2812, 2008.

17. Tang SN, Fu J, Nall D, Rodova M, Shankar S and Srivastava RK: Inhibition of sonic hedgehog pathway and pluripotency maintaining factors regulate human pancreatic cancer stem cell characteristics. Int J Cancer 131: 30-40, 2012.

18. Yao J, An Y, Wie JS, et al: Cyclopamine reverts acquired chemoresistance and down-regulates cancer stem cell markers in pancreatic cancer cell lines. Swiss Med Wkly 141: w13208, 2011.

19. Strand MF, Wilson SR, Dembinski JL, et al: A novel synthetic smoothened antagonist transiently inhibits pancreatic adenocarcinoma xenografts in a mouse model. PLoS One 6: e19904, 2011.

20. Nüsslein-Volhard $\mathrm{C}$ and Wieschaus E: Mutations affecting segment number and polarity in Drosophila. Nature 287: 795-801, 1980.

21. Hooper JE and Scott MP: Communicating with Hedgehogs. Nat Rev Mol Cell Biol 6: 306-317, 2005.

22. Kalderon D: Transducing the hedgehog signal. Cell 103: 371-374, 2000.

23. Kayed H, Kleeff J, Osman T, Keleg S, Büchler MW and Friess H: Hedgehog signaling in the normal and diseased pancreas. Pancreas 32: 119-129, 2006.

24. Berman DM, Karhadkar SS, Maitra A, et al: Widespread requirement for Hedgehog ligand stimulation in growth of digestive tract tumors. Nature 425: 846-851, 2003.

25. Kayed H, Kleeff J, Keleg S, et al: Indian hedgehog signaling pathway: expression and regulation in pancreatic cancer. Int J Cancer 110: 668-676, 2004

26. Thayer SP, di Magliano MP, Heiser PW, et al: Hedgehog is an early and late mediator of pancreatic cancer tumorigenesis. Nature 425: 851-856, 2003.

27. Gao J, Li Z, Chen Z, et al: Antisense Smo under the control of the PTCH1 promoter delivered by an adenoviral vector inhibits the growth of human pancreatic cancer. Gene Ther 13: 1587-1594, 2006.

28. Xu XF, Guo CY, Liu J, et al: Gli1 maintains cell survival by up-regulating IGFBP6 and $\mathrm{Bcl}-2$ through promoter regions in parallel manner in pancreatic cancer cells. J Carcinog 8: 13, 2009.

29. Yoo YA, Kang MH, Lee HJ, et al: Sonic hedgehog pathway promotes metastasis and lymphangiogenesis via activation of Akt, EMT, and MMP-9 pathway in gastric cancer. Cancer Res 71: 7061-7070, 2011.

30. Buonamici S, Williams J, Morrissey M, et al: Interfering with resistance to smoothened antagonists by inhibition of the PI3K pathway in medulloblastoma. Sci Transl Med 2: 51ra70, 2010.

31. Chen X, Lingala S, Khoobyari S, Nolta J, Zern MA and Wu J: Epithelial mesenchymal transition and hedgehog signaling activation are associated with chemoresistance and invasion of hepatoma subpopulations. J Hepatol 55: 838-845, 2011.
32. Singh SK, Clarke ID, Terasaki M, Bonn VE, Hawkins C, Squire J and Dirks PB: Identification of a cancer stem cell in human brain tumors. Cancer Res 63: 5821-5828, 2003.

33. Di Fiore R, Santulli A, Ferrante RD, et al: Identification and expansion of human osteosarcoma-cancer-stem cells by long-term 3-aminobenzamide treatment. J Cell Physiol 219: 301-313, 2009.

34. Tirino V, Desiderio V, d'Aquino R, et al: Detection and characterization of $\mathrm{CD}_{133^{+}}$cancer stem cells in human solid tumours PLoS One 3: e3469, 2008.

35. Mahller YY, Williams JP, Baird WH, et al: Neuroblastoma cell lines contain pluripotent tumor initiating cells that are susceptible to a targeted oncolytic virus. PLoS One 4: e4235, 2009.

36. Pode-Shakked N, Metsuyanim S, Rom-Gross E, et al: Developmental tumourigenesis: NCAM as a putative marker for the malignant renal stem/progenitor cell population. J Cell Mol Med 13: 1792-1808, 2009.

37. Walter D, Satheesha S, Albrecht $\mathrm{P}$, et al: CD133 positive embryonal rhabdomyosarcoma stem-like cell population is enriched in rhabdospheres. PLoS One 6: e19506, 2011.

38. Han YG, Spassky N, Romaguera-Ros M, Garcia-Verdugo JM, Aguilar A, Schneider-Maunoury S and Alvarez-Buylla A: Hedgehog signaling and primary cilia are required for the formation of adult neural stem cells. Nat Neurosci 11: 277-284, 2008.

39. Singh BN, Fu J, Srivastava RK and Shankar S: Hedgehog signaling antagonist GDC-0449 (Vismodegib) inhibits pancreatic cancer stem cell characteristics: molecular mechanisms. PLoS One 6: e27306, 2011.

40. Hermann PC, Huber SL, Herrler T, Aicher A, Ellwart JW and Guba M: Distinct populations of cancer stem cells determine tumor growth and metastatic activity in human pancreatic cancer. Cell Stem Cell 1: 313-323, 2007.

41. Dembinski JL and Krauss S: Characterization and functional analysis of a slow cycling stem cell-like subpopulation in pancreas adenocarcinoma. Clin Exp Metastasis 26: 611-623, 2009.

42. Feldmann G, Dhara S, Fendrich V, et al: Blockade of hedgehog signaling inhibits pancreatic cancer invasion and metastases: a new paradigm for combination therapy in solid cancers. Cancer Res 67: 2187-2196, 2007.

43. Maitah MY, Ali S, Ahmad A, Gadgeel S and Sarkar FH: Up-regulation of sonic hedgehog contributes to TGF- $\beta 1$-induced epithelial to mesenchymal transition in NSCLC cells. PLoS One 6: e16068, 2011.

44. Liao X, Siu MK, Au CW, et al: Aberrant activation of hedgehog signaling pathway in ovarian cancers: effect on prognosis, cell invasion and differentiation. Carcinogenesis 30: 131-140, 2009.

45. Olmeda D, Jordá M, Peinado H, Fabra A and Cano A: Snail silencing effectively suppresses tumour growth and invasiveness. Oncogene 26: 1862-1874, 2007.

46. Peinado H, Olmeda D and Cano A: Snail, Zeb and bHLH factors in tumour progression: an alliance against the epithelial phenotype? Nat Rev Cancer 7: 415-428, 2007. 